\title{
HUBUNGAN ANTARA PENGETAHUAN DAN SIKAP PERAWAT TENTANG DOKUMENTASI ASUHAN KEPERAWATAN DENGAN PENDOKUMENTASIAN ASUHAN KEPERAWATAN DI RUANG RAWAT INAP RSUD PATUT PATUH PATJU LOMBOK BARAT.
}

\author{
Ni Nyoman Santi Tri Ulandari, Eva Marvia \\ Staf Pengajar Sekolah Tinggi Ilmu Kesehatan Mataram
}

\begin{abstract}
Kekurangan dalam pendokumentasian asuhan keperawatan dapat mengakibatkan ketidakkonsistenan asuhan keperawatan dan tidak mampu mengevaluasi terapi yang efektif. Di RSUD Patut Patuh Patju Lombok Barat kekurangan tersebut dikarenakan pencatatannya tidak memenuhi kriteria standar dokumentasi yang berupa kelengkapan, akurasi dan relevansi. Pada studi pendahuluan yang peneliti lakukan pada 100 dokumen asuhan keperawatan didapatkan nilai keberhasilan dokumentasi pengkajian 26\%, diagnosa keperawatan 25\%, perencanaan 41\%, tindakan keperawatan 55\%, evaluasi $50 \%$.

Penelitian ini menggunakan desain penelitian korelasional dengan pendekatan cross sectional, jumlah populasi 57 orang dan besar sampel setelah dilakukan kriteria inklusi dan ekslusi didapatkan jumlah 50 orang responden dan 50 dokumentasi askep, tekhnik sampling menggunakan Purposive Sampling. Pengumpulan data pengetahuan dan sikap perawat dengan menggunakan kuesioner dan data pendokumentasian asuhan keperawatan menggunakan lembar observasi instrumen A dari Depkes yang kemudian dianalisa dengan menggunakan uji Spearman rank dengan taraf signifikansi $5 \%$.

Berdasarkan hasil analisa data didapatkan hubungan pengetahuan perawat tentang dokumentasi asuhan keperawatan dengan pendokumentasian asuhan keperawatan adalah $p=0,003$ dan tingkat hubungan rendah $(r=0,342)$, hubungan antara sikap perawat tentang dokumentasi asuhan keperawatan dengan pendokumentasian asuhan keperawatan adalah $p=0,024$ dan tingkat hubungan rendah $(r=0,246)$.

Perawat dengan pengetahuan yang baik cenderung melakukan pendokumentasian asuhan keperawatan dengan lengkap dan perawat dengan sikap yang tidak mendukung cenderung melakukan pendokumentasian asuhan keperawatan dengan tidak lengkap, sehingga kesimpulan penelitian ini adalah ada hubungan antara pengetahuan dan sikap perawat tentang dokumentasi asuhan keperawatan dengan pendokumentasian asuhan keperawatan di Ruang Rawat Inap RSUD Patut Patuh Patju Lombok Barat.
\end{abstract}

\section{Kata kunci : Pengetahuan, Sikap perawat, Pendokumentasian asuhan keperawatan.}

\section{PENDAHULUAN}

Datangnya era global dan otonomi menuntut suatu perubahan dan perkembangan dalam berbagai bidang termasuk dalam bidang keperawatan, yang mana hingga saat ini masih dalam proses profesionalisasi. Trends dan perubahan yang terjadi dalam sistem pelayanan kesehatan berpengaruh terhadap sistem dokumentasi keperawatan dan masalah-masalah kegiatan pencatatan oleh perawat dalam melaksanakan kegiatan sehari-hari (Nursalam, 2008). Dokumentasi keperawatan sendiri mempunyai makna yang penting dilihat dari berbagai aspek, antara lain : hukum, jaminan mutu, komunikasi, keuangan, pendidikan, penelitian dan akreditasi (Nursalam, 2008).

Melalui evaluasi dokumentasi keperawatan pada beberapa RSUD di Indonesia ditemukan bahwa kemampuan 
perawat dalam mendokumentasikan hasil asuhan keperawatan dengan menggunakan proses keperawatan rata-rata kurang dari $60 \%$ yang memenuhi kriteria (Keliat B.A, dkk, 1998). Sedangkan hasil evaluasi tim keperawatan di Rumah Sakit Cipto Mangunkusumo (RSCM) 1999 menyebutkan bahwa perawat yang melaksanakan pendokumentasian asuhan keperawatan sekitar 71\% (Azies, 2001). Hal ini juga tidak menutup kemungkinan pada RSUD lainnya termasuk RSUD Patut Patuh Patju Lombok Barat.

RSUD Patut Patuh Patju Lombok Barat merupakan rumah sakit type $\mathrm{C}$ yang memiliki jumlah perawat 108 orang, 85\% diantaranya berpendidikan DIII Keperawatan, 10\% berpendidikan SPK dan 5\% berpendidikan S1 Keperawatan. Dalam perkembangannya RSUD Patut Patuh Patju Lombok Barat telah mengintensifkan pelaksana n pendokumentasian asuhan keperawatan dengan menggunakan teknik dokumentasi keperawatan model Source Oriented Record (SOR) yang merupakan teknik dokumentasi yang dibuat oleh setiap anggota tim kesehatan dan dalam melaksanakan tindakan, mereka tidak bergantung pada tim lainnya, dengan model asuhan keperawatan yang digunakan adalah model asuhan tim. Model catatan menggunakan format untuk klien rawat inap yang didalamnya terdapat catatan pesanan dokter yang ditulis oleh dokter dan ada catatan riwayat keperawatan yang ditulis oleh perawat. Namun dalam pelaksanaannya perawat belum mendokumentasikan catatan riwayat keperawatan dengan lengkap dan jelas, pencatatan yang dilakukan belum memenuhi kriteria standart dokumentasi, dan hubungan antara pengetahuan dan sikap perawat tentang dokumentasi asuhan keperawatan dengan pendokumentasian asuhan keperawatan masih belum jelas.

Berdasarkan pengamatan awal yang dilakukan oleh peneliti pada bulan November 2011 menunjukkan bahwa kuantitas dokumentasi asuhan keperawatan di Ruang Rawat Inap Anak RSUD Patut Patuh Patju Lombok Barat masih kurang, dari 100 sampel dokumentasi asuhan keperawatan yang diobservasi didapatkan nilai keberhasilan dokumentasi pengkajian 26\%, diagnosa keperawatan $25 \%$, perencanaan $41 \%$, tindakan keperawatan 55\% dan evaluasi 50\%, sedangkan tinggi rendahnya mutu pelayanan keperawatan dapat digambarkan dari lengkap tidaknya data perawatan yang di dokumentasikan oleh perawat dalam rekam medik, keakuratan dalam pendokumentasian dan relevansi dokumentasi asuhan keperawatan. Sedangkan menurut PPNI (2000), standar praktik keperawatan profesional merupakan pedoman bagi perawat di Indonesia dalam melaksanakan asuhan keperawatan dengan menggunakan proses keperawatan. Standar praktik tersebut dilaksanakan oleh perawat generalis maupun spesialis di seluruh tatanan pelayanan kesehatan di rumah sakit, puskesmas maupun tatanan pelayanan kesehatan lain di masyarakat (Nursalam, 2011).

Standar praktik keperawatan profesional di Indonesia telah dijabarkan oleh Persatuan Perawat Nasional Indonesia (PPNI) pada tahun 2000. Standar tersebut mengacu pada proses keperawatan yang terdiri atas lima tahap, yaitu pengkajian, diagnosis, perencanaan, implementasi, dan evaluasi (Nursalam, 2011). Berdasarkan hal tersebut di atas, maka tujuan penelitian ini adalah untuk 
mengetahui apakah ada hubungan antara pengetahuan dan sikap perawat tentang dokumentasi asuhan keperawatan dengan pendokumentasian asuhan keperawatan di Ruang Rawat Inap RSUD Patut Patuh Patju Lombok Barat.

\section{METODE PENELITIAN}

Metode penelitian ini menggunakan metode deskriptif, digunakan untuk memecahkan atau menjawab permasalahan yang sedang dihadapi pada situasi sekarang (Notoatmodjo, 2010). Pada penelitian ini populasinya adalah seluruh perawat RSUD Patut Patuh Patju Lombok Barat yang bertugas di ruang rawat inap, dan jumlah perawat yang bertugas di Ruang Rawat Inap RSUD Patut Patuh Patju Lombok Barat adalah 57 orang. Pada penelitian ini peneliti menggunakan metode Purposive sampling, yaitu pengambilan sampel didasarkan pada suatu pertimbangan tertentu berdasarkan ciri atau sifat-sifat populasi yang sudah diketahui (Nursalam, 2008), Jumlah sample dalam penelitian ini sebanyak 50 orang perawat yang memenuhi kriteria inklusi dan eklusi.

Instrumen atau alat pengumpulan data pada penelitian ini menggunakan quisioner dan observasi. Sedangkan analisa data yang digunakan adalah menggunakan analisa Sperman Rho dengan bantuan SPSS. Penelitian tentang hubungan pengetahuan dan sikap perawat tentang dokumentasi asuhan keperawatan dengan pendokumentasian asuhan keperawatan ini menggunakan tehnik pengumpulan data struktur yaitu pengumpulan data penelitian disusun berdasarkan pengumpulan data yang benarbenar sesuai pada semua subjek, dan metode pengumpulan data kuantitatif yaitu data yang dikumpulkan disusun berdasarkan penghitungan sehingga dapat dianalisis secara statistic (Nursalam, 2008).

\section{HASIL PENELITIAN}

Tabel 1. data Pengetahuan Perawat tentang Dokumentasi Asuhan Keperawatan.

\begin{tabular}{|c|c|c|c|}
\hline No & Pengetahuan & Jumlah & $\begin{array}{c}\text { Prosentase } \\
(\%)\end{array}$ \\
\hline 1. & Baik & 27 & 54,0 \\
2. & Cukup & 21 & 42,0 \\
3. & Kurang & 2 & 4,0 \\
\hline \multicolumn{2}{|c|}{ Jumlah } & $\mathbf{5 0}$ & $\mathbf{1 0 0}$ \\
\hline
\end{tabular}

Sumber: Data Primer

Dari tabel 1 dapat diketahui bahwa hasil analisa data pengetahuan perawat tentang dokumentasi asuhan keperawatan di Ruang Rawat Inap RSUD Patut Patuh Patju Lombok Barat sebagian besar adalah baik yang berjumlah 27 responden (54\%), 21 responden (42\%) dengan pengetahuan cukup dan hanya 2 responden (4\%) yang pengetahuannya tentang dokumentasi asuhan keperawatan kurang. Pada kuesioner tentang pengetahuan, bagian yang jawabannya banyak salah dijawab oleh responden adalah konsep tentang dokumentasi asuhan keperawatan pada item faktor-faktor yang mempengaruhi dokumentasi asuhan keperawatan (21 orang) dan fungsi dokumentasi asuhan keperawatan (15 orang). Pada kategori pengetahuan yang baik nilai tertinggi adalah 10 (menjawab benar 10 pertanyaan dari 10 pertanyaan yang diajukan).

Tabel 2. Data Sikap Perawat tentang Dokumentasi Asuhan Keperawatan 


\begin{tabular}{|c|l|c|c|}
\hline $\begin{array}{c}\text { N } \\
\mathbf{0}\end{array}$ & \multicolumn{1}{|c|}{ Sikap } & $\begin{array}{c}\text { Jumla } \\
\text { h }\end{array}$ & $\begin{array}{c}\text { Prosenta } \\
\text { se (\%) }\end{array}$ \\
\hline 1. & Favorable/Menduk & 20 & 40,0 \\
2. & $\begin{array}{l}\text { ung } \\
\text { Unfavorable/Tidak } \\
\text { mendukung }\end{array}$ & 30 & 60,0 \\
\hline \multicolumn{1}{|l|}{ Jumlah } & $\mathbf{5 0}$ & $\mathbf{1 0 0}$ \\
\hline
\end{tabular}

Sumber: Data Primer

Dari tabel 2 dapat diketahui bahwa hasil analisa data sikap perawat tentang dokumentasi asuhan keperawatan di Ruang Rawat Inap RSUD Patut Patuh Patju Lombok Barat sebagian besar adalah unfavorable atau tidak mendukung dokumentasi asuhan keperawatan yaitu 30 responden (60\%) dan 20 orang $(40 \%)$ yang favorable atau mendukung dokumentasi asuhan keperawatan. Pada sikap perawat tentang dokumentasi asuhan keperawatan di Ruang Rawat Inap RSUD Patut Patuh Patju Lombok Barat yang terendah adalah sikap tentang standart dokumentasi asuhan keperawatan (5 responden dengan skor 1) sedangkan untuk skor tertinggi pada sikap adalah 38 .

a. Tabel 3. data Pendokumentasian Asuhan Keperawatan di Ruang Rawat Inap RSUD Patut Patuh Patju Lombok Barat. b.

\begin{tabular}{|l|l|c|c|}
\hline No & $\begin{array}{c}\text { Dokumentasi } \\
\text { Askep }\end{array}$ & Jumlah & $\begin{array}{c}\text { Prosentase } \\
(\%)\end{array}$ \\
\hline 1. & Tidak & 33 & 66,0 \\
2. & Lengkap & 17 & 34,0 \\
& Lengkap & & \\
\hline \multicolumn{2}{|c|}{ Jumlah } & $\mathbf{5 0}$ & $\mathbf{1 0 0}$ \\
\hline
\end{tabular}

Sumber: Data Primer

Dari tabel 3 dapat diketahui bahwa hasil analisa data pendokumentasian asuhan keperawatan di Ruang Rawat Inap RSUD Patut Patuh Patju Lombok Barat sebagian besar adalah tidak lengkap, yaitu berjumlah 33 rekam medik (66\%), sedangkan 17 rekam medik (34\%) pendokumentasian asuhan keperawatannya lengkap.

Berdasarkan hasil penilaian melalui observasi yang dilakukan di Ruang Rawat Inap RSUD Patut Patuh Patju Lombok Barat untuk kelengkapan pendokumentasian asuhan keperawatan yang jarang di isi adalah pengkajian pada pemeriksaan fisik terutama sistem organ, data psikologis dan data spiritual. Pada perencanaan, rumusan tujuan juga jarang diisi. Data tentang identitas, diagnosa, perencanaan, tindakan, evaluasi dan dokumentasi selalu di isi pada rekam medik. Nilai tertinggi untuk rekam medik dari segi kelengkapan rekam medik adalah 43 (84,3\%), sedangkan nilai terendah untuk kelengkapan rekam medik adalah $6(11,8 \%)$.

c. Tabel 4 analisa data hubungan pengetahuan perawat tentang dokumentasi asuhan keperawatan dengan pendokumentasian asuhan keperawatan di Ruang Rawat Inap RSUD Patut Patuh Patju Lombok Barat.

\begin{tabular}{|c|c|c|c|c|c|c|c|}
\hline \multirow{3}{*}{ No } & \multirow{3}{*}{ Pengetahuan } & \multicolumn{4}{|c|}{ Dokumentasi Askep } & \multirow{2}{*}{\multicolumn{2}{|c|}{ Jumlah }} \\
\hline & & \multicolumn{2}{|c|}{$\begin{array}{c}\text { Tidak } \\
\text { Lengkap }\end{array}$} & \multicolumn{2}{|c|}{ Lengkap } & & \\
\hline & & $\mathbf{n}$ & $\%$ & $\mathbf{n}$ & $\%$ & n & $\%$ \\
\hline 1. & Baik & 14 & 28 & 13 & 26 & 27 & 54 \\
\hline 2. & Cukup & 17 & 34 & 4 & 8 & 21 & 42 \\
\hline 3. & Kurang & 2 & 4 & 0 & 0 & 2 & 4 \\
\hline & Jumlah & 33 & 66 & 17 & 34 & 50 & 100 \\
\hline Spea & man Rank : Ko & asi $\mathrm{k}$ & $\begin{array}{l}\text { isie } \\
\text { val } \\
\alpha\end{array}$ & $\begin{array}{l}, 342 \\
0,00 \\
0,05\end{array}$ & & & \\
\hline
\end{tabular}

Sumber: Data Primer

Dari tabel 4 dapat diketahui bahwa terdapat hubungan antara pengetahuan perawat tentang dokumentasi asuhan keperawatan dengan pendokumentasian asuhan keperawatan di Ruang Rawat Inap RSUD Patut Patuh Patju Lombok Barat. Responden yang tingkat pengetahuan baik (54\%) lebih banyak yang menerapkan dokumentasi asuhan keperawatan secara tidak 
lengkap (28\%). Berdasarkan hasil analisa data dengan menggunakan Rank Spearman dengan taraf signifikansi 5\% didapatkan nilai $p$ kurang dari $0,05(p=0,03)$ dan korelasi koefisien 0,342 yang menunjukkan bahwa ada hubungan pada tingkat yang rendah antara pengetahuan perawat tentang dokumentasi a s uhan keperawatan dengan pendokumentasian asuhan keperawatan. Sehingga H0 (Hipotesis Nol) yaitu tidak ada hubungan antara pengetahuan perawat tentang dokumentasi asuhan keperawatan dengan pendokumentasian asuhan keperawatan ditolak, dan Ha (Hipotesis Alternatif) yaitu ada hubungan antara pengetahuan perawat tentang dokumentasi asuhan keperawatan dengan pendokumentasian asuhan keperawatan diterima.

d. Analisa data hubungan sikap perawat tentang dokumentasi asuhan keperawatan dengan pendokumentasian asuhan keperawatan di Ruang Rawat Inap RSUD Patut Patuh Patju Lombok Barat.

\begin{tabular}{|c|c|c|c|c|c|c|c|}
\hline \multirow{3}{*}{ No } & \multirow{3}{*}{ Sikap } & \multicolumn{4}{|c|}{ Dokumentasi Askep } & \multirow{2}{*}{\multicolumn{2}{|c|}{ Jumlah }} \\
\hline & & \multicolumn{2}{|c|}{$\begin{array}{c}\text { Tidak } \\
\text { Lengkap }\end{array}$} & \multicolumn{2}{|c|}{ Lengkap } & & \\
\hline & & $\mathbf{n}$ & $\%$ & $\mathbf{n}$ & $\%$ & $\mathbf{n}$ & $\%$ \\
\hline 1. & Mendukung & 9 & 18 & 11 & 22 & 20 & 40 \\
\hline 2. & $\begin{array}{l}\text { Tidak } \\
\text { mendukung }\end{array}$ & 24 & 48 & 6 & 12 & 30 & 60 \\
\hline & Jumlah & 33 & 66 & 17 & 34 & 50 & 100 \\
\hline \multicolumn{8}{|c|}{$\begin{array}{r}\text { Spearman Rank: Korelasi koefisien : } 0,246 \\
p \text { value }: 0,024 \\
\alpha \quad: 0,05\end{array}$} \\
\hline
\end{tabular}

Sumber: Data Primer

Dari tabel 5 dapat diketahui bahwa ada hubungan antara sikap perawat tentang dokumentasi asuhan keperawatan dengan pendokumentasian asuhan keperawatan di Ruang Rawat Inap RSUD Patut Patuh Patju Lombok Barat. Sikap perawat yang mendukung atau favorable (40\%) cenderung mengisi dokumentasi asuhan keperawatan secara lengkap (22\%). Sesuai dengan hasil analisa dengan menggunakan Rank Spearman dengan taraf significancy 5\% didapatkan hasil $p$ kurang dari 0,05 $(p=0,04)$ dan korelasi koefisien 0,246 yang menunjukkan bahwa ada hubungan pada tingkat yang rendah antara sikap perawat tentang dokumentasi asuhan keperawatan dengan pendokumentasian asuhan keperawatan. Sehingga H0 (Hipotesis Nol) yaitu tidak ada hubungan antara sikap perawat tentang dokumentasi asuhan keperawatan dengan pendokumentasian asuhan keperawatan ditolak, dan $\mathrm{Ha}$ (Hipotesis Alternatif) yaitu ada hubungan antara sikap perawat tentang dokumentasi as uhan keperawatan dengan pendokumentasian asuhan keperawatan diterima.

\section{Pembahasan}

Pengetahuan adalah merupakan hasil tahu, dan ini terjadi setelah orang melakukan penginderaan terhadap suatu objek tertentu. Penginderaan terjadi pada panca indera manusia, yaitu indera penglihatan, pendengaran, penciuman, rasa dan raba. Sebagian pengetahuan manusia diperoleh melalui mata dan telinga. Pengetahuan atau kognitif merupakan domain yang sangat penting untuk terbentuknya tindakan seseorang (over behavior). Perilaku yang didasari pengetahuan umumnya bersifat langgeng (Notoatmodjo, 2003).

Pengetahuan adalah segala bentuk pemahaman seseorang sebagai hasil dari pendidikan dan pengalaman hidup yang menyangkut segala sesuatu yang ada di sekitarnya. Pengetahuan di peroleh dari apa yang dirasakan dari panca indera manusia tentang gejala atau fenomena yang terjadi. 
Pengetahuan dapat diperoleh dari pendidikan, baik pendidikan formal ataupun pendidikan non formal, serta pengalaman hidup seseorang secara langsung maupun secara tidak langsung tentang segala fenomena kehidupan yang ada, karena tujuan dari pendidikan itu sendiri adalah untuk meningkatkan pengetahuan seseorang tentang sesuatu hal sehingga bisa menguasainya (Effendy, 2004). Tingkat pendidikan dan pengetahuan seseorang sangat menentukan dalam pengembangan kualitas sumber daya manusia itu sendiri.

Azwar (2011) menyatakan bahwa sikap positif akan menimbulkan keinginan untuk berbuat sesuatu. Sikap perawat terhadap pendokumentasian asuhan keperawatan merupakan suatu keadaan yang bersifat individual, mengingat terbentuknya sikap dapat dipengaruhi dari faktor intern dan faktor ekstern, disamping itu sikap juga dapat dibentuk secara bertahap melalui suatu proses tertentu, melalui kontak terus menerus antara individu dengan obyek sikap tersebut. Sikap dapat bersifat positif dan dapat pula bersifat negatif. Dalam sikap positif kecenderungan tindakan mendekati, menyenangi, mengharapkan obyek tertentu, sedangkan dalam sikap negatif terdapat kecenderungan untuk menjauhi, menghindari, membenci, tidak menyukai objek tertentu (Azwar, 2011). Sikap yang positif dari responden kemungkinan disebabkan pengalaman responden yang banyak dan masa kerja yang lama sehingga melahirkan pola pikir yang baik, keyakinan dan emosi yang baik. Sedangkan sikap yang negatif kemungkinan dikarenakan status kepegawaian responden yang mayoritas adalah tenaga kontrak (64\%) dan masa kerjanya 1-5 tahun, sehingga responden cenderung belum mempunyai motivasi yang baik dan kemampuan yang c ukup dalam melaksanakan pendokumentasian asuhan keperawatan di Ruang Rawat Inap RSUD Patut Patuh Patju Lombok Barat. Kemudian dari tabel 4.1 dan Tabel 4.3 didapatkan bahwa mayoritas responden adalah perempuan dan berstatus sudah menikah. Ibu-ibu yang bekerja perhatiannya cenderung terbagi antara pekerjaan dan keluarganya, sehingga responden kurang berkonsentrasi dalam melaksanakan pekerjaannya sebagai perawat terutama dalam pendokumentasian asuhan keperawatan. Menurut Thomas yang dikutip dalam Nursalam (2003), pekerjaan adalah keburukan yang harus dilakukan terutama untuk menunjang kehidupannya dan kehidupan keluarga. Pekerjaan bukanlah sumber kesenangan, tetapi lebih banyak merupakan cara mencari nafkah yang membosankan, berulang dan banyak tantangan. Sedangkan bekerja umumnya merupakan kegiatan yang menyita waktu. Bekerja bagi ibu-ibu akan mempunyai pengaruh terhadap kehidupan keluarga.

Berdasarkan paparan tersebut diatas, maka dalam melaksanakan pendokumentasian asuhan keperawatan perawat dituntut memiliki kemampuan intelektual, tekhnikal dan interpersonal. Hal ini sesuai dengan pendapat Carpenito (2000) bahwa dalam melaksanakan pendokumentasian asuhan keperawatan perawat harus memiliki kemampuan, kecakapan intelektual, keterampilan dalam berhubungan antar manusia dan keterampilan tekhnis.

Sikap merupakan kecenderungan bertindak dari individu, berupa respon tertutup terhadap stimulus ataupun objek tertentu (Sunaryo, 2002). Sikap juga merupakan reaksi atau 
respons yang masih tertutup dari seseorang terhadap suatu stimulus atau objek (Azwar, 2011). Menurut Kothandapani dalam Sunaryo (2002), bahwa struktur sikap terdiri dari komponen kognitif (kepercayaan), komponen emosional (perasaan), dan komponen perilaku (tindakan). Sedangkan menurut Azwar (2011) bahwa sikap memiliki tiga komponen yang membentuk struktur sikap, yang ketiganya saling menunjang, yaitu komponen kognitif, afektif, dan konatif. Sedangkan menurut Azwar (2011) ada dua faktor yang mempengaruhi sikap yaitu faktor internal dan faktor eksternal.

Apa yang telah dan sedang dialami seseorang akan ikut membentuk dan mempengaruhi penghayatan seseorang terhadap stimulus sosial. Tanggapan akan menjadi salah satu dasar terbentuknya sikap, untuk dapat mempunyai pengalaman yang berkaitan dengan objek psikologis. Tidak semua bentuk sikap yang ditentukan oleh situasi lingkungan dan pengalaman pribadi seseorang. Kadang-kadang suatu bentuk sikap merupakan pernyataan yang didasari oleh emosi yang berfungsi sebagai semacam penyaluran frustasi atau pengalihan bentuk mekanisme pertahanan ego (Azwar, 2011). Sikap juga dipengaruhi oleh faktor intelegensi, bakat, minat, perasaan serta kebutuhan dan motivasi seseorang.

Orang lain di sekitar merupakan salah satu diantara komponen sosial yang ikut mempengaruhi sikap seseorang. Seseorang yang dianggap penting, atau seseorang yang berarti khusus, akan banyak mempengaruhi pembentukan sikap seseorang terhadap sesuatu. Selain itu lembaga pendidikan dan lembaga agama sebagai suatu sistem mempunyai pengaruh dalam pembentukan sikap dikarenakan keduanya meletakkan dasar pengertian dan konsep moral dalam diri individu., pemahaman akan baik dan buruk, garis pemisah antara sesuatu yang boleh dan yang tidak boleh dilakukan, diperoleh dari pendidikan dan dari pusat keagamaan serta ajaran-ajarannya.

Dokumentasi asuhan keperawatan adalah pengumpulan, penyimpanan dan desiminasi informasi guna mempertahankan sejumlah fakta yang penting secara terus menerus pada suatu waktu, terhadap sejumlah kejadian (Nursalam, 2011). Dokumentasi keperawatan adalah suatu catatan yang dapat dibuktikan atau dijadikan bukti dari segala macam tuntutan, yang berisi data lengkap, nyata dan tercatat bukan hanya tentang tingkat kesakitan dari pasien, tetapi juga jenis atau tipe, kualitas dan kuantitas pelayanan kesehatan dalam memenuhi kebutuhan pasien (Fisbach,1991 dalam Tyo, 2009). Dokumentasi asuhan keperawatan merupakan suatu bukti pelayanan keperawatan yang berisi kegiatan pencatatan, pelaporan yang otentik dan penyimpanan semua kegiatan yang berkaitan dengan pengelolaan klien yang dapat dipergunakan untuk mengungkapkan suatu fakta aktual dan dapat dipertanggung jawabkan.

Proses keperawatan merupakan metode dimana suatu konsep diterapkan dalam praktek keperawatan disebut juga sebagai suatu pendekatan problem solving. Memerlukan ilmu, tehnik dan keterampilan interpersonal dan ditujukan untuk memenuhi kebutuhan klien atau keluarga. Carpenito (2000) menguraikan sistem dokumentasi keperawatan mempunyai beberapa komponen. Sebagian besar komponen terutama memfokuskan pada 
pendokumentasian sebagai berikut:

1. pengkajian keperawatan,

2. diagnosa keperawatan,

3. perencanaan keperawatan,

4. pelaksanaan keperawatan,

5. evaluasi keperawatan.

Dokumentasi bukan hanya syarat untuk akreditasi, tetapi juga syarat hukum di tatanan perawatan kesehatan. Dari fokus keperawatan, dokumentasi memberikan catatan tentang proses keperawatan untuk memberikan perawatan klien secara individual (Doengoes, 2000 ). Pendokumentasian dimulai dari pengkajian, identifikasi masalah, diagnosa keperawatan, perencanaan, implementasi rencana perawatan dan evaluasi yang semua dicatat dalam catatan perkembangan atau kemajuan.

Pada data hasil uji Rank Spearman didapatkan data hubungan pengetahuan perawat tentang dokumentasi asuhan keperawatan dengan pendokumentasian asuhan keperawatan di Ruang Rawat Inap RSUD Patut Patuh Patju Lombok Barat, yaitu nilai lebih kecil dari $0,05(=0,003)$. Sehingga ada hubungan antara pengetahuan perawat tentang dokumentasi asuhan keperawatan dengan pendokumentasian asuhan keperawatan dengan tingkat hubungan yang rendah karena correlation Coefficient (r) pada hubungan pengetahuan perawat tentang dokumentasi asuhan keperawatan dengan pendokumentasian asuhan keperawatan di Ruang Rawat Inap RSUD Patut Patuh Patju Lombok Barat berkisar antara 0,20-0,399.

Data yang menunjang kemaknaan tersebut, yaitu rata-rata responden mampu menjawab pertanyaan tentang konsep pendokumentasian asuhan keperawatan dengan hasil yang baik
(54\%) dengan skor maksimal pada kuesioner adalah 10 dari 10 item jumlah soal. Berdasarkan hasil observasi pada rekam medik didapatkan data bahwa perawat selalu mengisi pengkajian, menuliskan diagnosa, membuat perencanaan, menulis intervensi yang dilakukan, melakukan evaluasi dan selalu membuat dokumentasi tentang apa yang telah dilakukan.

Berdasarkan fakta di atas, maka ada hubungan pengetahuan perawat tentang dokumentasi asuhan keperawatan dengan pendokumentasian asuhan keperawatan di Ruang Rawat inap RSUD Patut patuh Patju Lombok Barat, artinya Hipotesa diterima.

Berdasarkan hal tersebut membuktikan bahwa pengetahuan (kognitif) merupakan domain yang sangat penting untuk tindakan seseorang dimana pengetahuan tersebut mengandung enam tingkatan domain kognitif yang mendominasi pengetahuan, pemahaman, penerapan atau aplikasi, analisis, sintesis dan evaluasi (Notoatmodjo, 2003). Menurut Nursalam (2008) dijelaskan bahwa pengetahuan berkaitan erat dengan perilaku manusia yaitu sebagai bentuk pengalaman dan interaksi individu dengan lingkungannya, sehingga untuk mendapatkan hasil dokumentasi proses keperawatan yang baik diperlukan pengetahuan dan keterampilan dalam bidang komunikasi, proses keperawatan dan penggunaan standar dokumentasi, proses keperawatan mulai dari dokumentasi pengkajian, diagnosa, perencanaan, tindakan dan evaluasi (Nursalam, 2008). Sedangkan pengetahuan dikembangkan melalui logika, intuisi, pengalaman, terutama kejadian-kejadian yang sama yang berulang dan dipengaruhi oleh pendidikan dan sosialisasi (Effendy, 2004). 
Di dalam praktek pemberian pelayanan asuhan keperawatan yang berkualitas diperlukan pengetahuan sebagai petunjuk dan dasar dalam memberikan intervensi keperawatan tetapi hal tersebut terkadang tidak disadari oleh perawat. Hal ini menunjukkan bahwa pengetahuan tentang dokumentasi asuhan keperawatan akan menstimulasi kinerja perawat dalam pendokumentasian asuhan keperawatan di Ruang Rawat Inap RSUD Patut patuh Patju Lombok Barat, karena perilaku yang didasari oleh pengetahuan akan lebih langgeng dari pada perilaku yang tidak didasari oleh pengetahuan. Hal tersebut diatas didukung oleh para perawat yang seluruhnya menjadi responden merupakan lulusan diploma III keperawatan. Artinya semakin tinggi pengetahuan perawat tentang pendokumentasian asuhan keperawatan, maka semakin baik pula kinerja perawat dalam pendokumentasian asuhan keperawatan.

\section{KESIMPULAN}

\section{A. Kesimpulan}

1. Dari 50 responden mayoritas responden mempunyai tingkat pengetahuan yang baik (54\%) tentang dokumentasi asuhan keperawatan di Ruang Rawat Inap RSUD Patut Patuh Patju Lombok Barat.

2. Dari 50 responden mayoritas responden menunjukkan sikap yang tidak mendukung atau unfavorable (60\%) dalam pendokumentasian asuhan keperawatan di Ruang Rawat Inap RSUD Patut Patuh Patju Lombok Barat.

3. Terdapat hubungan antara pengetahuan perawat tentang dokumentasi asuhan keperawatan dengan pendokumentasian asuhan keperawatan di Ruang Rawat Inap RSUD Patut Patuh Patju Lombok Barat.Hal ini dibuktikan dengan hasil uji Spearman Rank yang menunjukkan bahwa $p<0,05(p: 0,003)$.

\section{DAFTAR PUSTAKA.}

Azwar, Saifuddin., 2011. Sikap Manusia, Teori dan Pengukurannya. Edisi Ke2, Penerbit Pustaka Pelajar, Yogyakarta.

Carpenito,L.J., 1999. Rencana asuhan \& dokumentasi keperawatan, Terjemahan, Edisi ke-2, Penerbit Buku Kedokteran EGC, Jakarta.

Doenges, M.E., 1998. Penerapan Proses Keperawatan \& Diagnosa Keperawatan, Terjemahan, Edisi ke-2. Penerbit Buku Kedokteran EGC, Jakarta.

Effendy, 2004. Ilmu Dan Perannya Dalam Kehidupan, Alphabeta, Bandung Nursalam, 2008. Konsep dan Penerapan MetodologiPenelitian I l $m u$ Keperawatan,Edisi 2, PT. Salemba Medika,Jakarta.

, 2011. Proses Dan Dokumentasi Keperawatan, Konsep $\quad D$ a $n$ Praktik,Edisi 2, PT. Salemba Medika,Jakarta.

Sunaryo, 2002. Psikologi Untuk Keperawatan, Penerbit Buku Kedokteran EGC, Jakarta. 